\title{
Roles of the hemagglutinin of influenza $A$ virus in viral entry and development of antiviral therapeutics and vaccines
}

\author{
Shibo Jiang ${ }^{1,2}$, Runming $\mathrm{Li}^{2}$, Lanying $\mathrm{Du}^{1}$, Shuwen $\mathrm{Liu}^{2} \bowtie$ \\ ${ }^{1}$ Lindsley F. Kimball Research Institute, New York Blood Center, New York, NY 10065, USA \\ 2 School of Pharmaceutical Sciences, Southern Medical University, Guangzhou 510515, China \\ $₫$ Correspondence: sjiang@nybloodcenter.org (S. Jiang), liusw@smu.edu.cn (S. Liu) \\ Received March 24, 2010 Accepted March 31, 2010
}

\begin{abstract}
Seasonal influenza epidemics and influenza pandemics caused by influenza A virus (IAV) has resulted in millions of deaths in the world. The development of anti-IAV vaccines and therapeutics is urgently needed for prevention and treatment of IAV infection and for controlling future influenza pandemics. Hemagglutinin (HA) of IAV plays a critical role in viral binding, fusion and entry, and contains the major neutralizing epitopes. Therefore, HA is an attractive target for developing anti-IAV drugs and vaccines. Here we have reviewed the recent progress in study of conformational changes of HA during viral fusion process and development of HA-based antiviral therapeutics and vaccines.
\end{abstract}

KEYWORDS influenza A virus, hemagglutinin, viral entry, antiviral drugs, vaccines

\section{INTRODUCTION}

Influenza continues to pose serious threats to public health worldwide since seasonal influenza epidemics can affect up to $15 \%$ of the population and result in more than 500,000 deaths worldwide each year (http://www.who.int/csr/disease/ influenza/Research_Agenda_Document.pdf), while some influenza pandemics, like the 1918 flu pandemic (the Spanish Flu), may lead to millions of deaths (Taubenberger 2006). In 2009 , a new influenza pandemic caused by a novel swineorigin influenza A virus (S-OIV) $\mathrm{H} 1 \mathrm{~N} 1$ has resulted in millions of infections in more than 213 countries and overseas territories or communities (http://www.who.int/csr/don/ 2010_03_12/en/index.html) (Garten et al., 2009; Miller et al., 2009; Smith et al., 2009; Itoh et al., 2009). The rapid spread of S-OIV in humans worldwide and the continuous mutations of the S-OIV proteins (Pan and Jiang 2009; Pan et al., 2010) suggests that this newly emerging, animal-origin virus has acquired potent human-to-human transmissibility, which has raised a growing concern about the evolution of the highly pathogenic avian influenza (HPAl) H5N1 viruses that have caused 289 fatal cases among a total of 489 infected individuals, as of March 16, 2010, with a case-fatality rate of $\sim 60 \%$ (http://www.who.int/csr/disease/ avian_influenza/country/cases_table_2010_03_16/en/index.html) (the real H5N1 mortality rate should be closer to $14 \%-33 \%$ based on surveillance and seroprevalence studies conducted in several countries) (Li et al., 2008).

The influenza virus consists of three genera: A, B and C. Although all three types of influenza viruses are able to infect humans, only influenza A virus (IAV) may cause influenza pandemics (Watts 2009). Based on the antigenicity of the two surface proteins-hemagglutinin (HA) and neuraminidase (NA), IAV can be further classified into different subtypes including $16 \mathrm{HA}(\mathrm{H} 1-\mathrm{H} 16)$ and $9 \mathrm{NA}(\mathrm{N} 1-\mathrm{N} 9)$ subtypes (Yamashita et al., 2010). HA is responsible for the viral entry (Russell et al., 2008) and contains the major neutralizing epitopes (Ndifon et al., 2009), thus serving as an attractive target for drug and vaccine development.

\section{ROLE OF HA IN VIRAL ENTRY}

HA plays crucial roles in the early stage of virus infection, including virus binding to host receptors, viral entry, and membrane fusion (Skehel and Wiley, 2000). HA is initially synthesized as a precursor, HAO, which trimerizes in the endoplasmic reticulum in association with chaperones and is 
transferred to the cell surface through the Golgi apparatus. $\mathrm{HAO}$ is proteolytically cleaved into the functional HA1 and HA2 subunits linked by a single disulfide bond. Most influenza virus strains contain an HA cleavage site with only a single basic amino acid residue which is cleaved by tissue restricted proteases only, thereby limiting spread in the infected host. Cleavage occurs at the cell surface or on released viruses. For the $\mathrm{HAO}$ of the $\mathrm{H} 1, \mathrm{H} 2$, and $\mathrm{H} 3$ subtype viruses that have caused epidemics, cleavage may be mediated by the serine protease, tryptase Clara, produced by Clara cells of the bronchiolar epithelium (Kido et al., 1992). This enzyme shows recognition specificity for the sequence $Q / E-X-R$ found at the cleavage sites of these HAs. In contrast, for the $\mathrm{H} 5$ and $\mathrm{H} 7$ HPAl subtypes, the HA1 and HA2 polypeptide chains are separated by polybasic sequences that are inserted at the cleavage site (Perdue et al., 1997). In these cases, cleavage is intracellular and involves subtilisin-like enzymes that are active in the post-translational processing of hormone and growth factor precursors (Stieneke-Gröber et al., 1992). The furin recognition sequence $R-X-R / K-R$ is a common feature of the inserted polybasic sequences. The wide tissue distribution of furin-like enzymes and the high efficiency of intracellular cleavage, compared with extracellular cleavage, appear to be related to the widespread systemic and virulent infections caused by the $\mathrm{H} 5$ and $\mathrm{H} 7$ viruses in birds and the localized outbreak of H5N1 infection in humans in Hong Kong in 1997 (Steinhauer, 1999).

The receptors for IAV are sialic acids (Weis et al., 1988; Bullough et al., 1994; Liu et al., 2009). Depending on the species infected, the receptor recognition varies in specificity, which is the nature of the glycosidic linkage between sialic acid and the penultimate sugar of the side-chains (Rogers and Paulson, 1983). For example, the HAs of human IAVs bind with sialic acid in $\alpha-2,6$-linkage that is predominant in the upper human respiratory tracts (Matrosovich et al., 2004), whereas the HAs of avian IAVs prefer sialic acid in $\alpha-2,3-$ linkage to galactose, which predominates in the avian enteric tract (Naeve et al., 1984) (Fig. 1). Therefore, HA is a key component for an animal IAV to become transmissible in humans. For instance, an H5N1 IAV may acquire human-tohuman transmissibility if its HA gains the ability to bind to $\alpha$ 2,6-linked receptors (Stevens et al., 2006; Xu et al., 2010).
After binding to receptor, virus is taken into cells by endocytosis. Within the endosomal compartment, the virion is exposed to the increasing acid $\mathrm{pH} \mathrm{5-6,} \mathrm{the} \mathrm{HA} \mathrm{protein}$ undergoes an irreversible conformation change from its metastable prefusion conformation to a low- $\mathrm{pH}$ hairpin structure involving extrusion of the "fusion peptide (FP)" from the interior of the HA2 at the neutral-pH structure toward the endosomal membrane, promoting fusion of the viral and endosomal membranes (Harrison 2008; Reed et al., 2010). Xray crystallographic studies have demonstrated the extensive rearrangement of residues in $\mathrm{HA} 2$ at low $\mathrm{pH}$ with respect to their relative orientation and coil-coil formation, loop-to-helix or helix-to-loop transitions (Bullough et al., 1994; Durrer et al., 1996; Plotch et al., 1999; Harrison 2008).

At the initial step, de-trimerization of membrane distal HA1 domain is triggered by low $\mathrm{pH}$, while the domain remain tethered to the inner-core triple-stranded coiled coil structure of HA2 by the region of residues 28-43 (Bizebard et al., 1995). This step is driven by electrostatic forces because the positively charged HA1 favor the electrostatic interaction with the negatively charged HA2 in neutral $\mathrm{pH}$. The short helix (residues 38-55) and the extended loop (residues 56-75) in the N-terminal region of HA2 become an extension of the central triple-stranded coiled coil in the native HA to form a long helix (residues 38-104), relocating the FP over $100 \AA$ from its original buried position. At the same time, the middle portion (residues 105-112) of the long helix of HA2 converts to a loop, allowing the second half of the long helix to jackknife back to lie antiparallel against the first half (Fig. 2), resulting in formation of the hairpin structure, a common conformation presented in the class I transmembrane proteins of the enveloped viruses (Kielian and Rey 2006; Harrison, 2008).

The interaction between FP and the target membrane leads to an extended intermediate that bridges the viral and cell membranes. Then the intermediate collapses by zipping up of the C-terminal part of the ectodomain alongside the trimer-clustered $\mathrm{N}$-terminal part, which brings the two membranes into close proximity, resulting in formation of a hemifusion stalk. A fusion pore opens up, through which the genetic material of IAV is released into the host cell to generate new virions (Harrison, 2008).

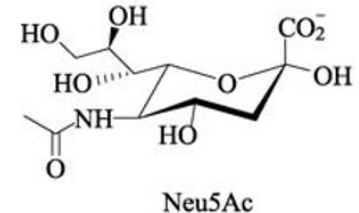

$\mathbf{A}$

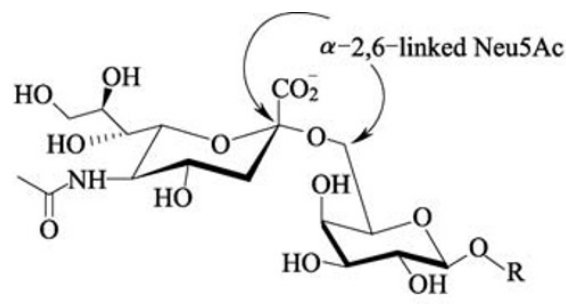

B

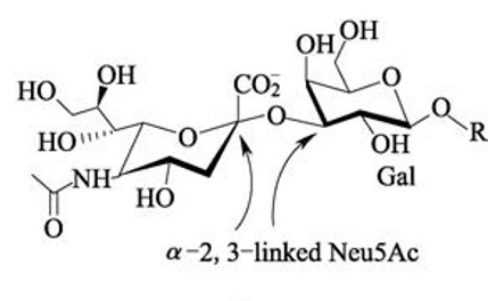

C

Figure 1. The glycosidic linkage between sialic acid and the penultimate sugar of the side-chains. (A) Sialic acid or $\mathrm{N}$ acetylneuraminic acid (Neu5Ac). (B) Ssialic acid in $\alpha-2,6$-linkage to galactose. (C) Sialic acid in $\alpha-2,3-$ linkage to galactose. 


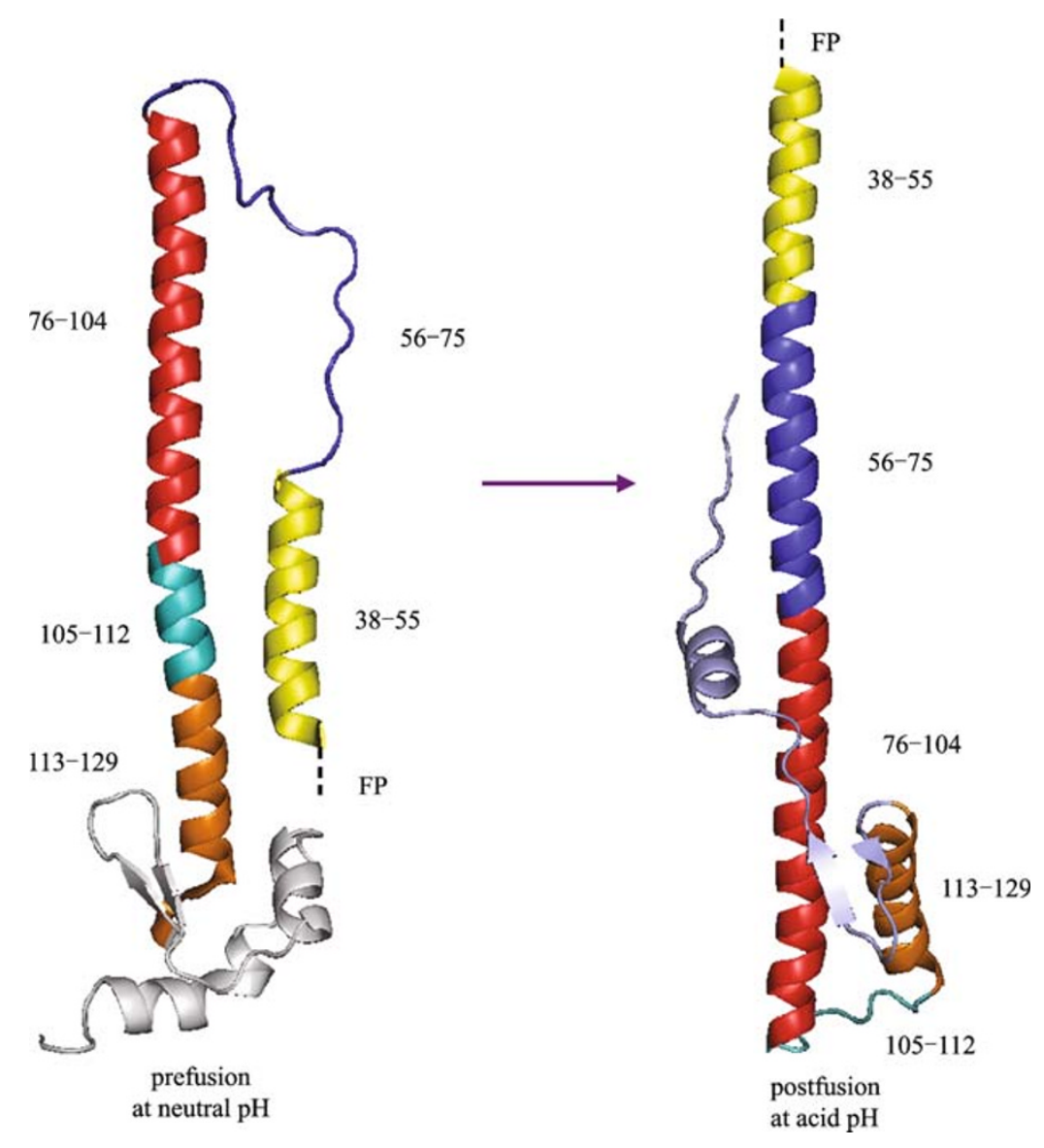

Figure 2. Diagrams of $\mathrm{pH}$-induced conformational change of HA2 subunit at the prefusion and postfusion states. In the prefusion state (at the neutral $\mathrm{pH}$ ), the each of the $\mathrm{HA} 2$ monomer in the homotrimer maintains a hairpin structure with the $\mathrm{N}$-terminal helix (residues 38-55) and C-terminal helix (residues 76-129) joined by an extended loop (residues 56-75) in antiparallel fashion. In the postfusion state (at the acid $\mathrm{pH}$ ), the each of the HA2 monomer still retains the hairpin structure. The middle portion (residues 105-112) of the original long helix unfolds to form a reverse turn and the C-terminal helix (residues 113-129) jack-knifes back to lie antiparallel against the newly formed N-terminal long helix (residues 38-104), resulting in the relocation of the FP (dash line) over $100 \AA$ from its previously buried position to the exposed position. The figure was prepared using the PyMol program (Delano, 2005) (http://www.pymol.org) and the X-ray crystal structures of HA at neutral pH (PDB ID: 2VIU) (Fleury et al., 1998) and low pH (PDB ID: 1HTM) (Bullough et al., 1994) downloaded from Protein Data Bank (http://www.rcsb.org/pdb/home/home.do).

\section{DEVELOPMENT OF ANTIVIRAL DRUGS TARGETING HA}

\section{IAV fusion inhibitors that suppress HAO cleavage}

Cleavage of the HA precursor HAO into the HA1 and HA2 subunits by host cell proteases, especially those in the airway, such as tryptase Clara (Kido et al., 1992), mini-plasmin (Murakami et al., 2001), and ectopic pancreatic trypsin (Le et al., 2006), is essential for subsequent steps of viral replication (Liu et al., 2009; Okumura et al., 2010). Therefore, any molecules that can block the cleavage of HAO may inhibit IAV infection (Kido et al., 2007). Several serine protease inhibitors, such as aprotinin, a 58-mer peptide (Zhirnov et al., 1984), leupeptin (also known as $N$-acetyl-L-leucyl-L-leucyl-Largininal) (Tashiro et al., 1987; Schröder et al., 1993), e-aminocaproic acid (Kido et al., 1992), nafamostat (Hosoya et al., 1992) (Fig. 3), pulmonary surfactant (a surface-active lipoprotein complex, phospholipoprotein, produced by type II alveolar cells) (Kido et al., 1993), human mucus protease inhibitor (Beppu et al., 1997), have been shown to reduce HA cleavage and IAV infection in cultures and animal models. Aprotinin (Trasylol, Bayer), a bovine pancreatic trypsin inhibitor, has been used as an injection drug for reduction of bleeding during complex surgery. However, Trasylol was withdrawn from the market in May 2008 after studies suggested that its use increased the risk of complications or death (http://www.trasylol.com/Trasylol_11_05_07.pdf). There are several FDA approved pulmonary surfactants in the market, including Exosurf, Curosurf, Infasurf, and Survanta, for increasing pulmonary compliance and preventing infant respiratory distress syndrome (IRDS). It has long 
leupeptin<smiles>CCCC(C(=O)NC(C=O)CCCNC(N)=[NH2+])N1CC(C)CC(NC(C)=O)C1=O</smiles><smiles>NCCCCCC(=O)O</smiles>

nafamostat<smiles>N=C(N)c1ccc2cc(OC(=O)c3ccc(N=C(N)N)cc3)ccc2c1</smiles>

Figure 3. The protein sequence and chemical structures of IAV inhibitors by suppressing the cleavage of the HA precursor HAO into the functional HA1 and HA2 subunits.

been known that the peptide substrate analog inhibitor (dec-R-V-K-R-cmk) against furin could block H7 HPAI IAV replication (Stieneke-Gröber et al., 1992). But later, it is observed that dec-R-V-K-R-cmk inhibits not only furin but also the ubiquitous type II transmembrane serine proteases, MSPL and its splice variant TMPRSS13, and other trypsintype protease such as plasmin (Okumura et al., 1997). Most recently, Kido and colleagues reported that MSPL/ TMPRSS13 may also serve as the HA processing proteases of $\mathrm{H} 5$ and $\mathrm{H} 7 \mathrm{HPAI}$ IAVs (Okumura et al., 2010). Therefore, the natural inhibitors of MSPL and TMPRSS13 in humans may also be used as leads for development of HA-based antiIAV drugs.

\section{IAV fusion inhibitors that block the pH-induced conformation change of HA}

During the HA-mediated membrane fusion, $\mathrm{HA}$ is activated in endosomes at acidic $\mathrm{pH}$ for induction of an irreversible reorganization of HA structure (Wilson et al., 1981; Bullough et al., 1994). Several small molecules that can block the $\mathrm{pH}$ depended conformational changes of $\mathrm{HA}$, such as benzoquinones and hydroquinones, were shown to inhibit IAV infection (Bodian et al., 1993). The most potent hydroquinone derivative is tert-butyl hydroquinone (TBHQ) (Fig. 4A), which inhibits IAV infection at low micromolar level (Bodian et al., 1993). Through an improved molecular docking analysis, the same group identified two new inhibitors with more potent IAV fusion inhibitory activity, S19 $\left(\mathrm{IC}_{50}=0.8 \mu \mathrm{M}\right)$ and C22 ( $\left.\mathrm{IC}_{50}=8 \mu \mathrm{M}\right)$ (Fig. 4A) (Hoffman et al., 1997). TBHQ could induce drug-resistance mutations in HA2 subunit (Hoffman et al., 1997), suggesting that it acts on the HA2 protein. X-ray crystallographic study indicates that $T B H Q$ binds with HA2 and locks the HA2 trimer at the neutral-pH conformation, through the interaction of $\mathrm{TBHQ}$ with three ionizable amino acids in this site: Arg-54 and Glu-57 from one HA2 monomer and Glu-97 from another HA2 monomer (Fig. 4B). Notably, TBHQ can inhibit H14 subtype avian influenza virus but has no inhibition on $\mathrm{H} 5$ subtype virus because the HA2 of $\mathrm{H} 5$ subtype has an intermonomer salt bridge between Lys-58 and Glu-97, while Glu-97 in HA2 of $\mathrm{H} 14$ subtype prefer to form salt bridge with Arg-54. As a result, Lys-58 in HA2 of $\mathrm{H} 14$ subtype is not well ordered, and the TBHQ site is accessible (Russell et al., 2008).

By screening a chemical library, scientists at Wyeth-Ayerst Research have identified three compounds, CL61917 (an Nsubstituted piperidine), CL 385319 (the 5-fluoro analog of CL 61917), and CL62554 (Fig. 5A), with inhibitory activity against $\mathrm{H} 1$ and $\mathrm{H} 2$ subtypes of $\mathrm{IAVs}$ with $\mathrm{IC}_{50}$ at low micromolar levels (Plotch et al., 1999). Analysis of HA genes of the mutant viruses resistant to these compounds showed that single amino acid mutations clustered in the stem region of the $\mathrm{HA}$ trimer in and near the HA2 FP. Computer-assisted molecular modeling revealed that CL61917 could dock into a pocket in this region. These results suggest that occupation of this pocket by CL61917 may interfere with the low $\mathrm{pH}$-induced structural rearrangements of $\mathrm{HA}$ by disrupting the ionic and hydrophobic forces that maintain $\mathrm{HA}$ at prefusogenic state or by blocking the movements of the polypeptide chain during the conformational reorganization (Plotch et al., 1999).

Researchers at the Shionogi Discovery Research Laboratories in Japan have identified several HA-mediated membrane fusion inhibitors, Stachyflin and its derivatives (Fig. 5B), purified from the fermentation broth of Stachybotrys $\mathrm{sp}$. 


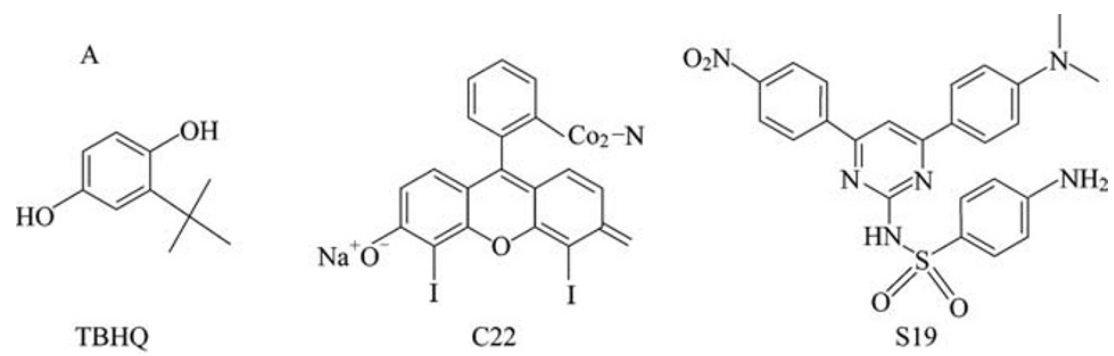

B

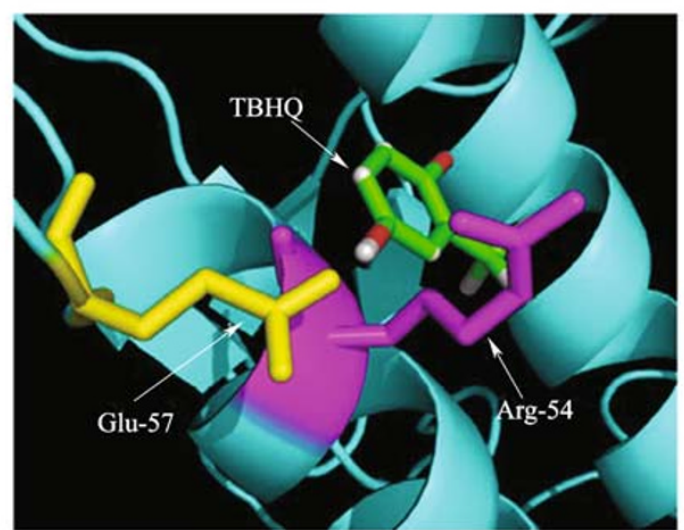

Figure 4. The chemical structures of TBHQ and its derivatives (A) and its binding to the HA2 subunit of H14 subtype IAV (B). The figure was prepared using the PyMol program and the X-ray crystal structures of HA in complex with TBHQ downloaded from Protein Data Bank (PDB ID: 3EYK) (Russell et al., 2008).

(Yoshimoto et al., 1999). Stachyflin is effective in inhibiting infection by $\mathrm{H} 1$ and $\mathrm{H} 2$ subtype $\mathrm{IAV}$ s with $\mathrm{IC}_{50}$ at low $\mu \mathrm{M}$ level. It was shown that Stachyflin interfered with low $\mathrm{pH}$-induced conformational change of $\mathrm{HA}$, thereby blocking HA-mediated virus-cell fusion. Analysis of the HA gene sequences of the $I A V$ variants with resistance to Stachyflin revealed that two amino acid substitutions, K51R and K121E, in the HA2 subunit of the HA protein, were enough to confer a Stachyflinresistant phenotype of HA protein (Yoshimoto et al., 2000a), suggesting that the binding site of Stachyflin is located in the HA2 subunit. The same group then designed and synthesized several Stachyflin derivatives, such as acetylstachyflin (Fig. 5B), with improved oral availability and antiviral activity (Yoshimoto et al., 2000b; Minagawa et al., 2002). But no further information about development of this class of anti-IAV drugs was available lately.

Investigators at Bristol Myers Squibb identified a novel IAV fusion inhibitor, BMY-27709 (Fig. 5C), which inhibited A/WSN/ 33 virus replication with $\mathrm{IC}_{50}$ at $3-8 \mu \mathrm{M}$ and was effective against all $\mathrm{H} 1$ and $\mathrm{H} 2$ subtype viruses tested (Luo et al., 1996). Further studies by this group indicated that BMY27709 inhibited IAV infection through its specific interaction with the HA protein to repress its conformational change of $\mathrm{HA}$ induced by low-pH. Sequence analyses of the HA gene of the variants resistant to BMY-27709 mapped the amino acid substitutions responsible for drug resistance to a region located near the $\mathrm{N}$ terminus of HA2, suggesting that this compound inhibits HA-mediated membrane fusion by targeting the N-terminal domain of HA2 subunit (Luo et al., 1997).

Researchers at Eli Lilly found that a podocarpic acid derivative, methyl-O-methyl-7-ketopodocarpate (LY-180299) (Fig. 5C) could effectively inhibit infection of A/Kawasaki/86 (H1N1) IAV strain by affecting an early step of viral replication (Staschke et al., 1998). Genetic analysis of the LY-180299sensitive and resistant reassortant viruses indicated that the HA protein conferred the 180299-resistant (180299r) phenotype and the mutations clustered in the interface between $\mathrm{HA} 1$ and $\mathrm{HA} 2$ and in a region near the FP of HA2. The $\mathrm{pH}$-ofinactivation of the resistant mutants was increased by $0.3-0.6 \mathrm{pH}$ unit, compared with the wild-type viruses. These data suggest that $\mathrm{LY}-180299$ may interact with the neutral $\mathrm{pH}$ conformation of $\mathrm{HA}$, resulting in prevention of the low- $\mathrm{pH}-$ induced change of $\mathrm{HA}$ to its fusogenic conformation.

\section{Peptidic IAV fusion/entry inhibitor targeting HA2}

In the early 1990s, several peptides derived from the HIV-1 gp41 HR2 domain were found to be highly potent in inhibiting gp41-mediated membrane fusion and HIV-1 replication (Jiang et al., 1993; Wild et al., 1994; Lu et al., 1995). One of the HR2peptides, T20 (generic name: enfuvirtide, brand name: Fuzeon) was licensed by the US FDA as the first member 
A<smiles>O=C(NCCN1CCCCC1)c1cccc(C(F)(F)F)c1</smiles>

CL 61917<smiles>O=C(NCCN1CCCCC1)c1cc(F)cc(C(F)(F)F)c1</smiles>

CL 385319<smiles>O=C1C2C(C(=O)N1Cc1cccnc1)C1(Cl)C(Cl)=C(Cl)C2(Cl)C1(Cl)Cl</smiles>

CL 62554

B<smiles>C[C@@H]1CC[C@H]2C(C)(C)[C@@H](O)CC[C@@]23Oc2c(c(O)cc4c2CNC4=N)C[C@]13C</smiles><smiles>CC(=O)O[C@H]1CC[C@@]2(CO1)Oc1c(O)cc3c(c1C[C@@]1(C)[C@H](C)CC[C@H]2C1(C)C)CNC3=N</smiles>

stachyflin

acetylstachyflin

C<smiles>C[C@H]1CCC[C@H]2C[C@H](NC(=O)c3cc(Cl)c(N)cc3O)CCN12</smiles>

BMY-27709<smiles>COC(=O)[C@]1(C)CCC[C@]2(C)c3cc(OC)ccc3C(=O)CC21</smiles>

LY-180299

Figure 5. The chemical structures of IAV inhibitors by interfering with the pH-induced conformation changes of HA2.

of a new class of anti-HIV drugs known as HIV fusion/entry inhibitors for the treatment of HIV-infected patients who fail to respond to the current antiretroviral therapeutics (Kilby and Eron, 2003). It was later proven that the HR2-peptides inhibited viral fusion by binding to the gp41 HR1 domain and interfering with the gp41 fusogenic six-helix bundle core formation (Chan et al., 1997; Weissenhorn et al., 1997; Liu et al., 2007). Discovery of anti-HIV peptides has opened new avenues for developing viral fusion/entry inhibitors against other viruses with class I membrane fusion proteins, such as respiratory syncytial virus (RSV), measles virus (Lambert et al., 1996), Ebola virus (Weissenhorn et al., 1998), Nipah and Hendra viruses (Xu et al., 2004a), and severe acute respiratory syndrome-associated coronavirus (SARS-CoV) (Liu et al., 2004; Xu et al., 2004b; Zhu et al., 2004). Since IAV is also a virus with class I membrane fusion proteins, several groups have attempted to identify T20-like anti-IAV peptides using similar approaches. But no success has been reported so far, possibly because of the limitations in developing antiIAV peptides. Unlike HIV-1 envelope glycoprotein gp120/ gp41 that change their conformation induced by receptor binding and mediate membrane fusion by acting on the cell surface at neutral $\mathrm{pH}$, the IAV HA mediates membrane fusion in the endosome at acid $\mathrm{pH}$. The peptides derived from the $\mathrm{HR} 2$ region of $\mathrm{HA} 2$, even they can interact with the HR1 region of $\mathrm{HA} 2$ in vitro at neutral $\mathrm{pH}$, may not be effective in inhibiting HA-mediated membrane fusion if the peptides cannot enter the cell and endosome or they become inactive at acid $\mathrm{pH}$. A chemical strategy, termed hydrocarbon stapling (Walensky et al., 2004), for designing cell-penetrating helical peptide with anti-HIV-1 activity (Zhang et al., 2008), may be adapted for developing anti-IAV peptides targeting the HA2 subunit of HA. Another strategy is to identify small molecule weight compounds with cell-penetrating ability or oral availability that can interact with the HR1 domain of HA and block the formation of trimer of heterodimer as IAV fusion/entry inhibitors. However, identification of proper "pocket" on the HR1-trimer at the prefusion or intermediate conformation is the prerequisite for screening small molecule anti-IAV compounds targeting HA2. The sequence of the pocket region in the HIV-1 gp41 HR1 domain is highly conserved and this hydrophobic pocket plays a critical role in viral fusion (Chan et al., 1998; Ji et al., 1999). Therefore, the peptidic HIV fusion inhibitor containing the pocket binding sequence, such 
as T-2544 (Dwyer et al., 2007) or small molecule HIV fusion inhibitor targeting the conserved pocket region, e.g., ADS-J1 (Wang et al., 2009) are reluctant to induce drug-resistance mutations because the virus may not survive the mutations in the highly conserved pocket region. Therefore, more efforts should be exerted in identification of peptidic or non-peptidic IAV fusion/entry inhibitors targeting sequence-conserved portion of HA, especially the interface of the coiled-coil contacts (Carr and Kim, 1993).

\section{DEVELOPMENT OF HA-BASED ANTI-IAV VACCINES}

Vaccination should be the most effective way to prevent or eliminate the future influenza pandemic. However, the currently licensed seasonal influenza vaccines are ineffective against the newly emerging influenza viruses. Therefore, development of vaccines against IAVs, especially those might induce highly pathogenic, i.e., HPAI H5N1, remains a priority.

Conventional approaches for development of influenza vaccines are mainly based on inactivated or live-attenuated influenza viruses (Treanor et al., 2006; Sasaki et al., 2007). These vaccines have shown promising efficiency, immunogenicity or cost-saving in clinical trials (Ruben 2004; Mitchell et al., 2005), but they have obvious disadvantages, including (i) the reliance on the availability of embryonated chicken eggs, which may be in short supply in a bird-flu outbreak, (ii) the length of vaccine generation time between the vaccine strain selection and the availability of the formulated vaccines, (iii) potential side effects on people who are allergy to egg protein, and (iv) the safety concerns for potential introduction of a live virus into human populations (Ellebedy and Webby, 2009). These limitations of conventional vaccines highlight the need for exploring new approaches for designing and developing influenza vaccines.

$\mathrm{HA}$, one of the most important IAV surface proteins, is the major target for inducing neutralizing antibody responses and thus a main constituent for all influenza vaccine formulations. Different categories of HA-based influenza vaccines have been developed, some of which are evaluated in clinical trials.

\section{HA-based DNA vaccines}

A variety of influenza vaccines have been developed based on the DNA encoding HAs of IAVs. Comparison of the efficacy of DNA vaccine coding HA protein (DNA-HA) with those coding other IAV proteins has demonstrated that DNA-HA is more effective in inducing high level of antibody and $T$ cell responses than the DNA vaccines encoding NA, nucleoprotein (NP) or matrix protein 2 (M2) protein, thus affording better protection than the others in preventing immunized mice from challenge with homologous or heterologous $\mathrm{H} 5 \mathrm{~N} 1$ viruses (Patel et al., 2009). In addition, the vaccination of mice with DNA-HA could significantly increase survival rate (Chen et al., 2009a). A clinical trial showed that a trivalent DNA vaccine consisting of three plasmids expressing HA of different seasonal influenza virus strains was safe and could elicit immunological responses that protected human subjects from A/H3 Panama/2007/99 virus challenge (Jones et al., 2009). A monovalent DNA vaccine containing an $A /$ Vietnam/1203/04 H5N1 HA-encoding plasmid was also shown to be safe and effective in Phase I clinical trials (Smith et al., 2010). However, DNA-based vaccines also have some disadvantages, including (i) risk of affecting genes that control cell growth, (ii) potential to induce anti-DNA antibody responses, and (iii) possible toxic effect to the injection sites when repeated doses are used (Du et al., 2008).

\section{HA-based viral vector vaccines}

Viral vectors have been selected as an alternative approach to develop HA-based vaccines. Reported viral vectors expressing HAs of influenza viruses include newcastle disease virus (NDV) (DiNapoli et al., 2010), parainfluenza virus type 5 (PIV5) (Tompkins et al., 2007), vesicular stomatitis virus (VSV) (Barefoot et al., 2009), adenovirus (Gao et al., 2006) and modified vaccinia virus Ankara (MVA) (Kreijtz et al., 2009a, b), and some of them have shown efficacy in preclinical trials. DiNapoli et al. reported that a NDV-vectored vaccine expressing HA of a HPAI H5N1 developed high levels of neutralizing antibodies against homologous and heterologous strains of HPAI IAVs and protected African green monkeys against homologous virus challenge (DiNapoli et al., 2010). According to Kreijtz et al., a recombinant MVA vector expressing the HA of A/Vietnam/ 1194/04 (H5N1) could induce cross-reactive antibody responses that protected vaccinated cynomolgus macaques from viral infection in the respiratory tract and prevented the development of severe necrotizing bronchointerstitial pneumonia (Kreijtz et al., 2009a). However, it should be noted that the immunogenicity of viral-vector-based vaccines could be suppressed by the presence of preexisting immunity to the vector, or the potential of causing harmful immune responses to vaccinated subjects (Barouch et al., 2004; Lasaro and Ertl 2009).

\section{HA-based virus-like particle vaccines}

Enveloped virus-like particle (VLP) vaccines containing HA and NA of influenza virus may be produced in insect or mammalian cells via simultaneously expression of the two proteins together with a viral core protein, such as M1 or a retroviral Gag protein (Haynes 2009). This new influenza vaccine approach provides overall advantages over the conventional methods to improve immunogenicity and protection. Previous results have demonstrated that VLPs containing H5N1 HA, NA and M proteins can induce high 
titers of $\mathrm{H} 5 \mathrm{~N} 1$-specific antibodies and/or long-term protection against heterologous as well as homologous H5N1 IAVs (Bright et al., 2008; Kang et al., 2009). A bivalent influenza VLP vaccine containing $H A$ of $H 1$ virus $A / P R / 8 / 34$ and $H 3$ virus $A / A i c h i / 2 / 68$ (X31) induced neutralizing activities and completely inhibited infection by the homologous strains and the heterologous strains, including $\mathrm{H} 1 \mathrm{~N} 1$ strains $\mathrm{A} / \mathrm{PR} / 8 / 34$ and $A / W S N / 33$ as well as $H 3 N 2$ strains $A / A i c h i / 2 / 68$ (X31) and $A /$ Hong Kong/68 of virus (Quan et al., 2008). This implies that influenza VLPs, particularly multivalent VLPs, can be used as an alternative method for developing safe and effective vaccines to control the spread of influenza viruses.

\section{HA-based recombinant subunit vaccines}

Recombinant subunit vaccines have been considered attractive for developing vaccines against IAVs (Amorij et al., 2007; Biesova et al., 2009) since this kind of vaccines generally contain no infectious materials, thus being non-infectious and safe to use ( $\mathrm{Du}$ et al., 2008). In addition, the currently available advanced recombinant technology would benefit the expeditious vaccine production. Furthermore, the high purity of the recombinant protein in the vaccine would enable administration at much higher doses without a significant increase in side effects in human subjects, especially those with immunodeficiency or high-risk medical conditions (Safdar and Cox, 2007). Currently, the HA-based subunit vaccines have been tested in various animal models or evaluated in human clinical trials (Wei et al., 2008; King et al., 2009). Reports have shown that an E-coli-expressed recombinant vaccine containing HA of A/Vietnam/1203/2004 (H5N1), formulated with alum, induced high immune responses, particularly HA-specific antibodies in young outbred mice, with the antibody levels consistent with the FDA guidelines for vaccines against epidemic and pandemic influenza (Biesova et al., 2009). Phase I clinical trial of a subunit influenza A/Hong Kong/1073/99 (H9N2) vaccine in healthy adults has shown that this subunit vaccine is safe and is able to induce antibody responses at the level similar to that induced by whole virus particles (Stephenson et al., 2003). Although they are safe and easy to produce, HA-based subunit vaccines might not induce strong immune responses, particularly in young children. This phenomenon is evidenced by a trivalent recombinant baculovirus-expressed HA influenza vaccine, which is shown to induce less immunogenicity than an egg-grown trivalent influenza vaccine in the healthy children aged 6-59 months (King et al., 2009). Therefore, it is crucial to improve the immunogenicity of HA-based subunit vaccines, in which the conformation of HA protein plays an important role. Recent studies have indicated the possibility of inducing stronger neutralizing antibody responses by $\mathrm{HA}$ in a high-molecular-weight oligomeric form than HAs in trimeric or monomeric forms (Wei et al., 2008).

\section{Vaccines based on the conserved HA sequences}

With the continuous threat of an influenza pandemic, there is an urgent need to develop vaccines that can provide protection not only against currently identified virus strains but also any future emerging virus strains. The rapid mutation of the protective $\mathrm{HA}$ antigen in the circulating IAVs requires reformulation of the influenza vaccines with broad specificity. As such, influenza vaccines directed against the conserved regions of the HA protein would have a great chance to meet these requirements.

The FP region of HA2 subunit contains conserved sequences that maintain high homology across all IAVs (Du et al., 2010). Recent studies have indicated that monoclonal antibody (mAb) CR6261, which recognizes a highly conserved helical region in the membrane-proximal stem of HA1 and HA2, could neutralize the virus by blocking conformational rearrangements associated with viral membrane fusion (Ekiert et al., 2009). Other studies have revealed that mAb $1 \mathrm{C}$, which binds to GLFGAIAGF of the conserved FP region of HA2, completely protected mice from lethal challenge of two different clades of HPAI H5N1 IAVs (Prabhu et al., 2009). Sui et al. have identified the broad neutralizing activity of an HA2-specific mAb (F10) with the binding sites located in a highly conserved FP-involved pocket in the stem region of $\mathrm{HA}$ (Sui et al., 2009).

In addition to conserved FP region, other conserved regions in the HA protein of IAVs may also serve as important vaccine targets. Human mAbs B-1 and D-1, which were recently obtained using the peripheral blood lymphocytes from two influenza-vaccinated volunteers, showed strong global neutralization of H3N2 strains, with the recognized sequences similar to the amino acid residues 173-181 and 227-239 of HA2 proteins, while these two sequences were fairly conserved in clearly separable clusters for H1N1, H3N2 and $\mathrm{H} 5 \mathrm{~N} 1$ with different host origins (Kubota-Koketsu et al., 2009; Yamashita et al., 2010). Another mAb 13D4, which mapped to at least two conserved sites of H5N1 HA, residues 152 and 182 in HA1, also protected mice against lethal challenge by four $\mathrm{H} 5 \mathrm{~N} 1$ strains that represent the current major genetic populations, clades 1, 2.1, 2.2 and 2.3 (Chen et al., 2009b). Using large-scale sequence analysis of the HA protein corresponding to $\mathrm{H} 1, \mathrm{H} 2, \mathrm{H} 3$ and $\mathrm{H} 5$ subtypes, Sahini et al. have identified nine conserved regions, five of which have the structural characteristics suitable for an anti-viral/ anti-peptide response (Sahini et al., 2010).

\section{CONCLUSION AND PROSPECTS}

$H A$, the major surface protein of IAV, mediates the viral binding, membrane fusion, and viral entry. Its receptor binding specificity determines the species specificity of IAV infection, e.g., HAs of human and avian IAVs preferably bind with sialic acids in $\alpha-2,6$ - and $\alpha-2,3-$ linkage, respectively. Further study 
is needed to understand the potential role of HA in the acquisition of human transmissibility by the animal-origin IAVs, such as the 2009 S-OIV H1N1 strain.

Determination of the crystal structures of HA0, HA1/HA2 complex, HA1/antibody complex, HA2/inhibitor complex, and HA2 trimer, provides important information for understanding of the $\mathrm{pH}$-induced conformational changes of $\mathrm{HA}$ at the prefusion, intermediate and postfusion states for identification of the targets in the HA-trimers at the prefusion and intermediate conformation, and for development of anti-IAV drugs. Given the fact that the sequences and conformations of the HAs in the H1, H2, and H3 subtype IAVs are much different from those of the H5 and H7 HPAl subtypes, it is worthwhile to explore the key residues which contribute the difference of conformations. Those key residues may be the "hot spots" for anti-IAV drug design and screening, especially for drugs against the high mortality H5N1 IAV.

Although a series of anti-IAV drugs targeting the NA and M2 proteins are currently available, the emergency of drugresistance viruses due to the widespread use of these drugs has raised the great concern on their ineffectiveness against the newly emerging IAVs, such as the 2009 S-OIV H1N1 strains and the HPAl viruses (Le et al., 2010; Mitrasinovic 2010). Thus, it is essential to develop novel anti-IAV drugs with new targets. A number of protein-based or small molecule anti-IAV agents have been shown to interfere with the HA-mediated membrane fusion by blocking the cleavage of HAO to the functional HA1 and HA2 subunits mediated by host proteases, or by inhibiting the low $\mathrm{pH}$-mediated conformation changes of HA. However, most of these drugs have low potency (at $\mu \mathrm{M})$ in inhibiting IAV replication. It is still a long way to develop these inhibitors as clinically usable antiIAV therapeutics. The successful strategy to discover and develop peptidic anti-HIV drug, T20 (enfuvirtide) has been applied for identification of peptidic fusion inhibitors against other viruses bearing the class I transmembrane proteins, including IAV. However, no such anti-IAV peptide has been ever reported, suggesting the difficulty to identify a peptide that can enter into the cell and endosome to block the fusion between viral and endosomal membranes mediated by HA at acid $\mathrm{pH}$ environment. There are hopes to design or screen cell-permissible short peptides or small molecular weight organic compounds that can interact with targets on the HR1trimer and block the formation of the HA fusion-active core. Though the peptidic drugs are expensive, it is worthwhile to develop if they can save lives of the patients during the influenza pandemics.

Because of the antigen shift and drift, it is a great challenge to develop effective and safe vaccines against divergent IAVs, especially those newly emerging HPAl subtypes that may cause future influenza pandemic. Since HA contains the major neutralizing epitopes, it serves an important target for developing anti-IAV vaccines. A number of HA-based DNA vaccines, viral vector vaccines, virus-like particle vaccines, and recombinant subunit vaccines have been developed under preclinical and clinical studies. The identification of the neutralizing epitopes in the conserved FP and other regions of HA proteins demonstrate the potential of these conserved regions in serving as important vaccine targets, accordingly bringing some hopes for the development of influenza vaccines that may induce cross-protection against divergent IAVs (Ekiert et al., 2009; Prabhu et al., 2009; Sui et al., 2009; Du et al., 2010). More and more effective epitopes are expected to be found in the conserved regions of HA as vaccine targets for future prevention of an influenza pandemic.

\section{ACKNOWLEDGEMENTS}

We thank Chungen Pan for assistance in preparing the Fig. 4B. SJ and LD were supported by the US NIH grants (Nos. Al68002, Al46221), and SL and RL were supported by the Natural Science Foundation of China (Grant No. 30772602) and the Ministry of Education's New Century Talent Program (NCET-06-0753).

\section{ABBREVIATIONS}

DNA-HA, DNA vaccine coding HA protein; FP, fusion peptide; HA, hemagglutinin; HPAI, highly pathogenic avian influenza; IAV, influenza A virus; IRDS, infant respiratory distress syndrome; mAb, monoclonal antibody; MVA, modified vaccinia virus Ankara; M2, matrix protein 2; NA, neuraminidase; NDV, newcastle disease virus; NP, nucleoprotein; PIV5, parainfluenza virus type 5; RSV, respiratory syncytial virus; SARS-CoV, severe acute respiratory syndromeassociated coronavirus; S-OIV, swine-origin influenza A virus; VLP, enveloped virus-like particle; VSV, vesicular stomatitis virus

\section{REFERENCES}

Amorij, J.P., Meulenaar, J., Hinrichs, W.L., Stegmann, T., Huckriede, A., Coenen, F., and Frijlink, H.W. (2007). Rational design of an influenza subunit vaccine powder with sugar glass technology: preventing conformational changes of haemagglutinin during freezing and freeze-drying. Vaccine 25, 6447-6457.

Barefoot, B.E., Athearn, K., Sample, C.J., and Ramsburg, E.A. (2009). Intramuscular immunization with a vesicular stomatitis virus recombinant expressing the influenza hemagglutinin provides post-exposure protection against lethal influenza challenge. Vaccine 28, 79-89.

Barouch, D.H., Pau, M.G., Custers, J.H., Koudstaal, W., Kostense, S., Havenga, M.J., Truitt, D.M., Sumida, S.M., Kishko, M.G., Arthur, J. C., et al (2004). Immunogenicity of recombinant adenovirus serotype 35 vaccine in the presence of pre-existing anti-Ad5 immunity. J Immunol 172, 6290-6297.

Beppu, Y., Imamura, Y., Tashiro, M., Towatari, T., Ariga, H., and Kido, $H$. (1997). Human mucus protease inhibitor in airway fluids is a potential defensive compound against infection with influenza $A$ and Sendai viruses. J Biochem 121, 309-316.

Biesova, Z., Miller, M.A., Schneerson, R., Shiloach, J., Green, K.Y., Robbins, J.B., and Keith, J.M. (2009). Preparation, characterization, and immunogenicity in mice of a recombinant influenza $\mathrm{H} 5$ hemagglutinin vaccine against the avian H5N1 A/Vietnam/1203/ 
2004 influenza virus. Vaccine 27, 6234-6238.

Bizebard, T., Gigant, B., Rigolet, P., Rasmussen, B., Diat, O., Bösecke, P., Wharton, S.A., Skehel, J.J., and Knossow, M. (1995). Structure of influenza virus haemagglutinin complexed with a neutralizing antibody. Nature 376, 92-94.

Bodian, D.L., Yamasaki, R.B., Buswell, R.L., Stearns, J.F., White, J. M., and Kuntz, I.D. (1993). Inhibition of the fusion-inducing conformational change of influenza hemagglutinin by benzoquinones and hydroquinones. Biochemistry 32, 2967-2978.

Bright, R.A., Carter, D.M., Crevar, C.J., Toapanta, F.R., Steckbeck, J. D., Cole, K.S., Kumar, N.M., Pushko, P., Smith, G., Tumpey, T.M.et al (2008). Cross-clade protective immune responses to influenza viruses with $\mathrm{H} 5 \mathrm{~N} 1 \mathrm{HA}$ and NA elicited by an influenza virus-like particle. PLoS One 3, e1501.

Bullough, P.A., Hughson, F.M., Skehel, J.J., and Wiley, D.C. (1994). Structure of influenza haemagglutinin at the $\mathrm{pH}$ of membrane fusion. Nature 371, 37-43.

Carr, C.M., and Kim, P.S. (1993). A spring-loaded mechanism for the conformational change of influenza hemagglutinin. Cell 73 , 823-832.

Chan, D.C., Fass, D., Berger, J.M., and Kim, P.S. (1997). Core structure of gp41 from the HIV envelope glycoprotein. Cell 89 , 263-273.

Chan, D.C., Chutkowski, C.T., and Kim, P.S. (1998). Evidence that a prominent cavity in the coiled coil of HIV type $1 \mathrm{gp} 41$ is an attractive drug target. Proc Natl Acad Sci U S A 95, 15613-15617.

Chen, Q., Kuang, H., Wang, H., Fang, F., Yang, Z., Zhang, Z., Zhang, $X$., and Chen, Z. (2009a). Comparing the ability of a series of viral protein-expressing plasmid DNAs to protect against H5N1 influenza virus. Virus Genes 38, 30-38.

Chen, Y., Qin, K., Wu, W.L., Li, G., Zhang, J., Du, H., Ng, M.H., Shih, J.W., Peiris, J.S., Guan, Y., et al. (2009b). Broad cross-protection against $\mathrm{H} 5 \mathrm{~N} 1$ avian influenza virus infection by means of monoclonal antibodies that map to conserved viral epitopes. $J$ Infect Dis 199, 49-58.

Delano, W.L.2005. The PyMOL molecular graphics system (http:// www.pymol.org). DeLano Scientific LLC. 400, Oyster Point Blvd., Suite 213, South San Francisco, CA 94080-1918 USA.

DiNapoli, J.M., Nayak, B., Yang, L., Finneyfrock, B.W., Cook, A., Andersen, H., Torres-Velez, F., Murphy, B.R., Samal, S.K., Collins, P.L., et al. (2010). Newcastle disease virus-vectored vaccines expressing the hemagglutinin or neuraminidase protein of H5N1 highly pathogenic avian influenza virus protect against virus challenge in monkeys. J Virol 84, 1489-1503.

Du, L., He, Y., Jiang, S., and Zheng, B.J. (2008). Development of subunit vaccines against severe acute respiratory syndrome. Drugs Today (Barc) 44, 63-73.

Du, L., Zhou, Y., and Jiang, S. (2010). Research and development of universal influenza vaccines. Microbes Infect 12, 280-286.

Durrer, P., Galli, C., Hoenke, S., Corti, C., Glück, R., Vorherr, T., and Brunner, J. (1996). H +-induced membrane insertion of influenza virus hemagglutinin involves the HA2 amino-terminal fusion peptide but not the coiled coil region. J Biol Chem 271, 13417-13421.

Dwyer, J.J., Wilson, K.L., Davison, D.K., Freel, S.A., Seedorff, J.E., Wring, S.A., Tvermoes, N.A., Matthews, T.J., Greenberg, M.L., and Delmedico, M.K. (2007). Design of helical, oligomeric HIV-1 fusion inhibitor peptides with potent activity against enfuvirtide-resistant virus. Proc Natl Acad Sci U S A 104, 12772-12777.

Ekiert, D.C., Bhabha, G., Elsliger, M.A., Friesen, R.H., Jongeneelen, M., Throsby, M., Goudsmit, J., and Wilson, I.A. (2009). Antibody recognition of a highly conserved influenza virus epitope. Science 324, 246-251.

Ellebedy, A.H., and Webby, R.J. (2009). Influenza vaccines. Vaccine 27, D65-D68.

Fleury, D., Wharton, S.A., Skehel, J.J., Knossow, M., and Bizebard, T. (1998). Antigen distortion allows influenza virus to escape neutralization. Nat Struct Biol 5, 119-123.

Gao, W., Soloff, A.C., Lu, X., Montecalvo, A., Nguyen, D.C., Matsuoka, Y., Robbins, P.D., Swayne, D.E., Donis, R.O., Katz, J. M., et al. (2006). Protection of mice and poultry from lethal H5N1 avian influenza virus through adenovirus-based immunization. $J$ Virol 80, 1959-1964.

Garten, R.J., Davis, C.T., Russell, C.A., Shu, B., Lindstrom, S., Balish, A., Sessions, W.M., Xu, X., Skepner, E., Deyde, V., et al. (2009). Antigenic and genetic characteristics of swine-origin 2009 A (H1N1) influenza viruses circulating in humans. Science 325 , 197-201.

Harrison, S.C. (2008). Viral membrane fusion. Nat Struct Mol Biol 15, 690-698.

Haynes, J.R. (2009). Influenza virus-like particle vaccines. Expert Rev Vaccines 8, 435-445.

Hoffman, L.R., Kuntz, I.D., and White, J.M. (1997). Structure-based identification of an inducer of the low-pH conformational change in the influenza virus hemagglutinin: irreversible inhibition of infectivity. J Virol 71, 8808-8820.

Hosoya, M., Matsuyama, S., Baba, M., Suzuki, H., and Shigeta, S. (1992). Effects of protease inhibitors on replication of various myxoviruses. Antimicrob Agents Chemother 36, 1432-1436.

Itoh, Y., Shinya, K., Kiso, M., Watanabe, T., Sakoda, Y., Hatta, M., Muramoto, Y., Tamura, D., Sakai-Tagawa, Y., Noda, T., et al. (2009). In vitro and in vivo characterization of new swine-origin H1N1 influenza viruses. Nature 460, 1021-1025.

Ji, H., Shu, W., Burling, T., Jiang, S., and Lu, M. (1999). Inhibition of HIV-1 infectivity by the gp41 core: role of a conserved hydrophobic cavity in membrane fusion. J Virol 73, 8578-8586.

Jiang, S., Lin, K., Strick, N., and Neurath, A.R. (1993). HIV-1 inhibition by a peptide. Nature $365,113$.

Jones, S., Evans, K., McElwaine-Johnn, H., Sharpe, M., Oxford, J., Lambkin-Williams, R., Mant, T., Nolan, A., Zambon, M., Ellis, J., et al. (2009). DNA vaccination protects against an influenza challenge in a double-blind randomised placebo-controlled phase 1b clinical trial. Vaccine 27, 2506-2512.

Kang, S.M., Yoo, D.G., Lipatov, A.S., Song, J.M., Davis, C.T., Quan, F. S., Chen, L.M., Donis, R.O., Compans, R.W., and Broliden, K. (2009). Induction of long-term protective immune responses by influenza H5N1 virus-like particles. PLoS ONE 4, e4667.

Kido, H., Yokogoshi, Y., Sakai, K., Tashiro, M., Kishino, Y., Fukutomi, A., and Katunuma, N. (1992). Isolation and characterization of a novel trypsin-like protease found in rat bronchiolar epithelial Clara cells. A possible activator of the viral fusion glycoprotein. J Biol Chem 267, 13573-13579.

Kido, H., Sakai, K., Kishino, Y., and Tashiro, M. (1993). Pulmonary surfactant is a potential endogenous inhibitor of proteolytic activation of Sendai virus and influenza A virus. FEBS Lett 322, $115-119$ 
Kido, H., Okumura, Y., Yamada, H., Le, T.Q., and Yano, M. (2007). Proteases essential for human influenza virus entry into cells and their inhibitors as potential therapeutic agents. Curr Pharm Des 13, 405- 414.

Kielian, M., and Rey, F.A. (2006). Virus membrane-fusion proteins: more than one way to make a hairpin. Nat Rev Microbiol 4, 67-76.

Kilby, J.M., and Eron, J.J. (2003). Novel therapies based on mechanisms of HIV-1 cell entry. N Engl J Med 348, 2228-2238.

King, J.C. Jr, Cox, M.M., Reisinger, K., Hedrick, J., Graham, I., and Patriarca, P. (2009). Evaluation of the safety, reactogenicity and immunogenicity of FluBlok trivalent recombinant baculovirusexpressed hemagglutinin influenza vaccine administered intramuscularly to healthy children aged 6-59 months. Vaccine 27 , 6589-6594.

Kreijtz, J.H., Suezer, Y., de Mutsert, G., van den Brand, J.M., van Amerongen, G., Schnierle, B.S., Kuiken, T., Fouchier, R.A., Löwer, J., Osterhaus, A.D., et al. (2009a). Preclinical evaluation of a modified vaccinia virus Ankara (MVA)-based vaccine against influenza A/H5N1 viruses. Vaccine 27, 6296-6299.

Kreijtz, J.H., Suezer, Y., de Mutsert, G., van den Brand, J.M., van Amerongen, G., Schnierle, B.S., Kuiken, T., Fouchier, R.A., Löwer, J., Osterhaus, A.D., et al. (2009b). Recombinant modified vaccinia virus Ankara expressing the hemagglutinin gene confers protection against homologous and heterologous H5N1 influenza virus infections in macaques. J Infect Dis 199, 405-413.

Kubota-Koketsu, R., Mizuta, H., Oshita, M., Ideno, S., Yunoki, M., Kuhara, M., Yamamoto, N., Okuno, Y., and Ikuta, K. (2009). Broad neutralizing human monoclonal antibodies against influenza virus from vaccinated healthy donors. Biochem Biophys Res Commun 387, 180-185.

Lambert, D.M., Barney, S., Lambert, A.L., Guthrie, K., Medinas, R., Davis, D.E., Bucy, T., Erickson, J., Merutka, G., and Petteway, S.R. Jr. (1996). Peptides from conserved regions of paramyxovirus fusion $(F)$ proteins are potent inhibitors of viral fusion. Proc Natl Acad Sci U S A 93, 2186-2191.

Lasaro, M.O., and Ertl, H.C. (2009). New insights on adenovirus as vaccine vectors. Mol Ther 17, 1333-1339.

Le, T.Q., Kawachi, M., Yamada, H., Shiota, M., Okumura, Y., and Kido, H. (2006). Identification of trypsin I as a candidate for influenza $A$ virus and Sendai virus envelope glycoprotein processing protease in rat brain. Biol Chem 387, 467-475.

Le, Q.M., Wertheim, H.F., Tran, N.D., van Doorn, H.R., Nguyen, T.H., and Horby, P., and the Vietnam H1N1 Investigation Team. (2010). A community cluster of oseltamivir-resistant cases of $2009 \mathrm{H} 1 \mathrm{~N} 1$ influenza. N Engl J Med 362, 86-87.

Li, F.C., Choi, B.C., Sly, T., and Pak, A.W. (2008). Finding the real case-fatality rate of $\mathrm{H} 5 \mathrm{~N} 1$ avian influenza. J Epidemiol Community Health 62, 555-559.

Liu, S., Xiao, G., Chen, Y., He, Y., Niu, J., Escalante, C.R., Xiong, H., Farmar, J., Debnath, A.K., Tien, P., et al. (2004). Interaction between heptad repeat 1 and 2 regions in spike protein of SARSassociated coronavirus: implications for virus fusogenic mechanism and identification of fusion inhibitors. Lancet 363, 938-947.

Liu, S., Wu, S., and Jiang, S. (2007). HIV entry inhibitors targeting gp41: from polypeptides to small-molecule compounds. Curr Pharm Des 13, 143-162.

Liu, J., Stevens, D.J., Haire, L.F., Walker, P.A., Coombs, P.J., Russell, R.J., Gamblin, S.J., and Skehel, J.J. (2009). Structures of receptor complexes formed by hemagglutinins from the Asian Influenza pandemic of 1957. Proc Natl Acad Sci U S A 106, 17175-17180.

Lu, M., Blacklow, S.C., and Kim, P.S. (1995). A trimeric structural domain of the HIV-1 transmembrane glycoprotein. Nat Struct Biol 2, 1075-1082.

Luo, G., Colonno, R., and Krystal, M. (1996). Characterization of a hemagglutinin-specific inhibitor of influenza A virus. Virology 226, 66-76.

Luo, G., Torri, A., Harte, W.E., Danetz, S., Cianci, C., Tiley, L., Day, S., Mullaney, D., Yu, K.L., Ouellet, C., et al. (1997). Molecular mechanism underlying the action of a novel fusion inhibitor of influenza A virus. J Virol 71, 4062-4070.

Matrosovich, M.N., Matrosovich, T.Y., Gray, T., Roberts, N.A., and Klenk, H.D. (2004). Human and avian influenza viruses target different cell types in cultures of human airway epithelium. Proc Natl Acad Sci U S A 101, 4620-4624.

Miller, M.A., Viboud, C., Balinska, M., and Simonsen, L. (2009). The signature features of influenza pandemics-implications for policy. N Engl J Med 360, 2595-2598.

Minagawa, K., Kouzuki, S., and Kamigauchi, T. (2002). Stachyflin and acetylstachyflin, novel anti-influenza A virus substances, produced by Stachybotrys sp. RF-7260. II. Synthesis and preliminary structure-activity relationships of stachyflin derivatives. J Antibiot (Tokyo) 55, 165-171.

Mitchell, D.K., Ruben, F.L., and Gravenstein, S. (2005). Immunogenicity and safety of inactivated influenza virus vaccine in young children in 2003-2004. Pediatr Infect Dis J 24, 925-927.

Mitrasinovic, P.M. (2010). Advances in the structure-based design of the influenza A neuraminidase inhibitors. Curr Drug Targets 11, 315-326.

Murakami, M., Towatari, T., Ohuchi, M., Shiota, M., Akao, M., Okumura, Y., Parry, M.A., and Kido, H. (2001). Mini-plasmin found in the epithelial cells of bronchioles triggers infection by broad-spectrum influenza A viruses and Sendai virus. Eur J Biochem 268, 2847-2855.

Naeve, C.W., Hinshaw, V.S., and Webster, R.G. (1984). Mutations in the hemagglutinin receptor-binding site can change the biological properties of an influenza virus. J Virol 51, 567-569.

Ndifon, W., Wingreen, N.S., and Levin, S.A. (2009). Differential neutralization efficiency of hemagglutinin epitopes, antibody interference, and the design of influenza vaccines. Proc Natl Acad Sci U S A 106, 8701-8706.

Okumura, Y., Sato, H., Seiki, M., and Kido, H. (1997). Proteolytic activation of the precursor of membrane type 1 matrix metalloproteinase by human plasmin. A possible cell surface activator. FEBS Lett 402, 181-184.

Okumura, Y., Takahashi, E., Yano, M., Ohuchi, M., Daidoji, T., Nakaya, T., Bottcher, E., Garten, W., Klenk, H.D., and Kido, H. (2010). Novel type II transmembrane serine proteases, MSPL and TMPRSS13, proteolytically activate membrane fusion activity of hemagglutinin of highly pathogenic avian influenza viruses and induce their multicycle replication. J Virol, 10.

Pan, C. and Jiang, S. (2009). E14-F55 combination in M2 protein: a putative molecular determinant responsible for swine-origin influenza A virus transmission in humans. PLoS Curr Influenza RRN1044.

Pan, C., Cheung, B., Tan, S., Li, C., Li, L., Liu, S., and Jiang, S. (2010). Genomic signature and mutation trend analysis of pandemic 
(H1N1) 2009 influenza A virus. PLoS ONE 5, e9549.

Patel, A., Tran, K., Gray, M., Li, Y., Ao, Z., Yao, X., Kobasa, D., and Kobinger, G.P. (2009). Evaluation of conserved and variable influenza antigens for immunization against different isolates of H5N1 viruses. Vaccine 27, 3083-3089.

Perdue, M.L., García, M., Senne, D., and Fraire, M. (1997). Virulenceassociated sequence duplication at the hemagglutinin cleavage site of avian influenza viruses. Virus Res 49, 173-186.

Plotch, S.J., O'Hara, B., Morin, J., Palant, O., LaRocque, J., Bloom, J. D., Lang, S.A.J. Jr, DiGrandi, M.J., Bradley, M., Nilakantan, R., et al. (1999). Inhibition of influenza A virus replication by compounds interfering with the fusogenic function of the viral hemagglutinin. $J$ Virol 73, 140-151.

Prabhu, N., Prabakaran, M., Ho, H.T., Velumani, S., Qiang, J., Goutama, M., and Kwang, J. (2009). Monoclonal antibodies against the fusion peptide of hemagglutinin protect mice from lethal influenza A virus H5N1 infection. J Virol 83, 2553-2562.

Quan, F.S., Steinhauer, D., Huang, C., Ross, T.M., Compans, R.W., and Kang, S.M. (2008). A bivalent influenza VLP vaccine confers complete inhibition of virus replication in lungs. Vaccine 26 , 3352-3361.

Reed, M.L., Bridges, O.A., Seiler, P., Kim, J.K., Yen, H.L., Salomon, R., Govorkova, E.A., Webster, R.G., and Russell, C.J. (2010). The $\mathrm{pH}$ of activation of the hemagglutinin protein regulates $\mathrm{H} 5 \mathrm{~N} 1$ influenza virus pathogenicity and transmissibility in ducks. J Virol 84, 1527-1535.

Rogers, G.N., and Paulson, J.C. (1983). Receptor determinants of human and animal influenza virus isolates: differences in receptor specificity of the $\mathrm{H} 3$ hemagglutinin based on species of origin. Virology 127, 361-373.

Ruben, F.L. (2004). Inactivated influenza virus vaccines in children. Clin Infect Dis 38, 678-688.

Russell, R.J., Kerry, P.S., Stevens, D.J., Steinhauer, D.A., Martin, S. R., Gamblin, S.J., and Skehel, J.J. (2008). Structure of influenza hemagglutinin in complex with an inhibitor of membrane fusion. Proc Natl Acad Sci U S A 105, 17736-17741.

Safdar, A., and Cox, M.M. (2007). Baculovirus-expressed influenza vaccine. A novel technology for safe and expeditious vaccine production for human use. Expert Opin Investig Drugs 16, 927-934.

Sahini, L., Tempczyk-Russell, A., Agarwal, R., and Lau, A.T.Y. (2010). Large-scale sequence analysis of hemagglutinin of influenza $A$ virus identifies conserved regions suitable for targeting an anti-viral response. PLoS ONE 5, e9268.

Sasaki, S., Jaimes, M.C., Holmes, T.H., Dekker, C.L., Mahmood, K., Kemble, G.W., Arvin, A.M., and Greenberg, H.B. (2007). Comparison of the influenza virus-specific effector and memory B-cell responses to immunization of children and adults with live attenuated or inactivated influenza virus vaccines. J Virol 81, 215-228.

Schröder, E., Phillips, C., Garman, E., Harlos, K., and Crawford, C. (1993). X-ray crystallographic structure of a papain-leupeptin complex. FEBS Lett 315, 38-42.

Skehel, J.J., and Wiley, D.C. (2000). Receptor binding and membrane fusion in virus entry: the influenza hemagglutinin. Annu Rev Biochem 69, 531-569.

Smith, G.J.D., Vijaykrishna, D., Bahl, J., Lycett, S.J., Worobey, M., Pybus, O.G., Ma, S.K., Cheung, C.L., Raghwani, J., Bhatt, S., et al.
(2009). Origins and evolutionary genomics of the 2009 swineorigin H1N1 influenza A epidemic. Nature 459, 1122-1125.

Smith, L.R., Wloch, M.K., Ye, M., Reyes, L.R., Boutsaboualoy, S., Dunne, C.E., Chaplin, J.A., Rusalov, D., Rolland, A.P., Fisher, C.L., et al. (2010). Phase 1 clinical trials of the safety and immunogenicity of adjuvanted plasmid DNA vaccines encoding influenza $A$ virus $\mathrm{H} 5$ hemagglutinin. Vaccine 28, 2565-2572.

Staschke, K.A., Hatch, S.D., Tang, J.C., Hornback, W.J., Munroe, J. E., Colacino, J.M., and Muesing, M.A. (1998). Inhibition of influenza virus hemagglutinin-mediated membrane fusion by a compound related to podocarpic acid. Virology 248, 264-274.

Steinhauer, D.A. (1999). Role of hemagglutinin cleavage for the pathogenicity of influenza virus. Virology 258, 1-20.

Stephenson, I., Nicholson, K.G., Glück, R., Mischler, R., Newman, R. W., Palache, A.M., Verlander, N.Q., Warburton, F., Wood, J.M., and Zambon, M.C. (2003). Safety and antigenicity of whole virus and subunit influenza A/Hong Kong/1073/99 (H9N2) vaccine in healthy adults: phase I randomised trial. Lancet 362, 1959-1966.

Stevens, J., Blixt, O., Tumpey, T.M., Taubenberger, J.K., Paulson, J. C., and Wilson, I.A. (2006). Structure and receptor specificity of the hemagglutinin from an H5N1 influenza virus. Science 312 , 404-410.

Stieneke-Gröber, A., Vey, M., Angliker, H., Shaw, E., Thomas, G., Roberts, C., Klenk, H.D., and Garten, W. (1992). Influenza virus hemagglutinin with multibasic cleavage site is activated by furin, a subtilisin-like endoprotease. EMBO J 11, 2407-2414.

Sui, J., Hwang, W.C., Perez, S., Wei, G., Aird, D., Chen, L.M., Santelli, E., Stec, B., Cadwell, G., Ali, M., et al. (2009). Structural and functional bases for broad-spectrum neutralization of avian and human influenza A viruses. Nat Struct Mol Biol 16, 265-273.

Tashiro, M., Klenk, H.D., and Rott, R. (1987). Inhibitory effect of a protease inhibitor, leupeptin, on the development of influenza pneumonia, mediated by concomitant bacteria. J Gen Virol 68, 2039-2041.

Taubenberger, J.K. (2006). The origin and virulence of the 1918 "Spanish" influenza virus. Proc Am Philos Soc 150, 86-112.

Tompkins, S.M., Lin, Y., Leser, G.P., Kramer, K.A., Haas, D.L., Howerth, E.W., Xu, J., Kennett, M.J., Durbin, R.K., Durbin, J.E., et al. (2007). Recombinant parainfluenza virus 5 (PIV5) expressing the influenza $A$ virus hemagglutinin provides immunity in mice to influenza A virus challenge. Virology 362, 139-150.

Treanor, J.J., Campbell, J.D., Zangwill, K.M., Rowe, T., and Wolff, M. (2006). Safety and immunogenicity of an inactivated subvirion influenza A (H5N1) vaccine. N Engl J Med 354, 1343-1351.

Walensky, L.D., Kung, A.L., Escher, I., Malia, T.J., Barbuto, S., Wright, R.D., Wagner, G., Verdine, G.L., and Korsmeyer, S.J. (2004). Activation of apoptosis in vivo by a hydrocarbon-stapled $\mathrm{BH} 3$ helix. Science 305, 1466-1470.

Wang, H., Qi, Z., Guo, A., Mao, Q., Lu, H., An, X., Xia, C., Li, X., Debnath, A.K., Wu, S., et al. (2009). ADS-J1 inhibits HIV-1 entry by interacting with the gp41 pocket region and blocking the fusionactive gp41 core formation. Antimicrob Agents Chemother 53, 4987-4998.

Watts, G. (2009). A/H1N1 influenza virus: the basics. BMJ 339 , b3046.

Wei, C.J., Xu, L., Kong, W.P., Shi, W., Canis, K., Stevens, J., Yang, Z. Y., Dell, A., Haslam, S.M., Wilson, I.A., et al. (2008). Comparative efficacy of neutralizing antibodies elicited by recombinant hemag- 
glutinin proteins from avian H5N1 influenza virus. J Virol 82, 6200-6208.

Weis, W., Brown, J.H., Cusack, S., Paulson, J.C., Skehel, J.J., and Wiley, D.C. (1988). Structure of the influenza virus haemagglutinin complexed with its receptor, sialic acid. Nature 333, 426-431.

Weissenhorn, W., Dessen, A., Harrison, S.C., Skehel, J.J., and Wiley, D.C. (1997). Atomic structure of the ectodomain from HIV-1 gp41. Nature 387, 426-430.

Weissenhorn, W., Carfí, A., Lee, K.H., Skehel, J.J., and Wiley, D.C. (1998). Crystal structure of the Ebola virus membrane fusion subunit, GP2, from the envelope glycoprotein ectodomain. Mol Cell 2, 605-616.

Wild, C.T., Shugars, D.C., Greenwell, T.K., McDanal, C.B., and Matthews, T.J. (1994). Peptides corresponding to a predictive $\alpha-$ helical domain of human immunodeficiency virus type $1 \mathrm{gp} 41$ are potent inhibitors of virus infection. Proc Natl Acad Sci U S A 91, 9770-9774.

Wilson, I.A., Skehel, J.J., and Wiley, D.C. (1981). Structure of the haemagglutinin membrane glycoprotein of influenza virus at $3 \mathrm{~A}$ resolution. Nature 289, 366-373.

Xu, Y., Gao, S., Cole, D.K., Zhu, J., Su, N., Wang, H., Gao, G.F., and Rao, Z. (2004a). Basis for fusion inhibition by peptides: analysis of the heptad repeat regions of the fusion proteins from Nipah and Hendra viruses, newly emergent zoonotic paramyxoviruses. Biochem Biophys Res Commun 315, 664-670.

Xu, Y., Lou, Z., Liu, Y., Pang, H., Tien, P., Gao, G.F., and Rao, Z. (2004b). Crystal structure of severe acute respiratory syndrome coronavirus spike protein fusion core. J Biol Chem 279, 49414-49419.

Xu, R., McBride, R., Paulson, J.C., Basler, C.F., and Wilson, I.A. (2010). Structure, receptor binding, and antigenicity of influenza virus hemagglutinins from the $1957 \mathrm{H} 2 \mathrm{~N} 2$ pandemic. J Virol 84,
1715-1721.

Yamashita, A., Kawashita, N., Kubota-Koketsu, R., Inoue, Y., Watanabe, Y., Ibrahim, M.S., Ideno, S., Yunoki, M., Okuno, Y., Takagi, T., et al. (2010). Highly conserved sequences for human neutralization epitope on hemagglutinin of influenza $A$ viruses H3N2, H1N1 and H5N1: Implication for human monoclonal antibody recognition. Biochem Biophys Res Commun 393, 614-618.

Yoshimoto, J., Kakui, M., Iwasaki, H., Fujiwara, T., Sugimoto, H., and Hattori, N. (1999). Identification of a novel HA conformational change inhibitor of human influenza virus. Arch Virol 144, 865-878.

Yoshimoto, J., Kakui, M., Iwasaki, H., Sugimoto, H., Fujiwara, T., and Hattori, N. (2000a). Identification of amino acids of influenza virus HA responsible for resistance to a fusion inhibitor, Stachyflin. Microbiol Immunol 44, 677-685.

Yoshimoto, J., Yagi, S., Ono, J., Sugita, K., Hattori, N., Fujioka, T., Fujiwara, T., Sugimoto, H., and Hashimoto, N. (2000b). Development of anti-influenza drugs: II. Improvement of oral and intranasal absorption and the anti-influenza activity of stachyflin derivatives. J Pharm Pharmacol 52, 1247-1255.

Zhang, H., Zhao, Q., Bhattacharya, S., Waheed, A.A., Tong, X., Hong, A., Heck, S., Curreli, F., Goger, M., Cowburn, D., et al. (2008). A cell-penetrating helical peptide as a potential HIV-1 inhibitor. J Mol Biol 378, 565-580.

Zhirnov, O.P., Ovcharenko, A.V., and Bukrinskaya, A.G. (1984). Suppression of influenza virus replication in infected mice by protease inhibitors. J Gen Virol 65, 191-196.

Zhu, J., Xiao, G., Xu, Y., Yuan, F., Zheng, C., Liu, Y., Yan, H., Cole, D. K., Bell, J.I., Rao, Z., et al. (2004). Following the rule: formation of the 6-helix bundle of the fusion core from severe acute respiratory syndrome coronavirus spike protein and identification of potent peptide inhibitors. Biochem Biophys Res Commun 319, 283-288. 